\title{
Homeopathic Pathogenetic Trials Produce Specific Symptoms Different from Placebo
}

\author{
Heribert Möllinger ${ }^{\mathrm{a}}$ Rainer Schneider ${ }^{\mathrm{b}}$ Harald Walach $^{\mathrm{c}}$ \\ a Private Practice, Amriswil, Switzerland \\ ${ }^{\mathrm{b}}$ Department of Human Sciences, University of Osnabrück, Germany \\ ${ }^{\mathrm{c}}$ School of Social Sciences and Samueli Institute, European Office, University of Northampton, UK
}

\section{Key Words}

Homeopathy · Placebo · Double-blind · Randomised controlled trial · RCT · Pathogenetic trial

\section{Summary}

Introduction: Homeopathy uses information gathered from healthy volunteers taking homeopathic substances (pathogenetic trials) for clinical treatment. It is controversial whether such studies produce symptoms different from those produced by placebo. Objective: To test whether homeopathic preparations produce different symptoms than placebo in healthy volunteers. Methods: Three armed, double-blind, placebo controlled randomised experimental pathogenetic study in 25 healthy volunteers who took either one of two homeopathic remedies, Natrum muriaticum and Arsenicum album in $30 \mathrm{CH}$ or identical placebo. Main outcome parameter was the number of remedy-specific symptoms per group. Results: On average, 6 symptoms typical for Arsenicum album were experienced by participants taking arsenicum album, 5 symptoms typical for Natrum muriaticum by those taking natrum muriaticum, and 11 non-specific symptoms by those in the placebo group. Differences were significant overall (Kruskall Wallis test, $p=0.0002$,) and significantly different from placebo (Mann-Whitney test, $p=0.001$ ). Conclusion: Homeopathic remedies produce different symptoms than placebo.

\author{
Schlüsselwörter \\ Homöopathie - Placebo - Doppelblind - Randomisierte \\ kontrollierte Studie · RCT · Arzneimittelprüfung
}

\section{Zusammenfassung}

Einleitung: In der Homöopathie werden Symptome für die Therapie verwendet, die von gesunden Freiwilligen bei der Einnahme homöopathischer Substanzen beobachtet wurden. Es ist unklar, ob diese Symptome sich von Placebosymptomen unterscheiden. Ziel: Untersuchung der Frage, ob Arzneimittelsymptome und Placebosymptome bei gesunden Freiwilligen unterscheidbar sind. Methode: Dreiarmige, doppelblinde, placebokontrollierte, randomisierte, experimentelle Arzneimittelprüfung an 25 gesunden Freiwilligen, die entweder zwei homöopathische Arzneien, Arsenicum album oder Natrium muriaticum jeweils in C30, einnahmen oder ununterscheidbares Placebo. Zielkriterium war die Zahl der arzneimitteltypischen Symptome je Gruppe. Ergebnisse: Personen, die Arsenicum album einnahmen berichteten im Durchschnitt 6 Symptome, die für Arsen typisch sind. Personen, die Natrum muriaticum einnahmen, berichteten durchschnittlich 5 Symptome, die für Natrum muriaticum typisch sind, und Placebo-Probanden berichteten durchschnittlich 11 Symptome, die unspezifisch waren. Die Unterschiede zwischen den Gruppen waren signifikant (Kruskall-Wallis-Test, $p=0,0002$ ) und die experimentellen Ergebnisse der homöopathischen Gruppen signifikant von Placebo verschieden (separate Mann-Whitney-Tests, $p=0,001)$. Schlussfolgerung: Homöopathische Arzneien erzeugen andere Symptome als Placebo.

\begin{tabular}{ll}
\hline KARGER & @ 2009 S. Karger GmbH, Freiburg \\
Fax +497614520714 & Accessible online at: \\
Information@Karger.de & www.karger.com/fok \\
www.karger.com &
\end{tabular}




\section{Introduction and Background}

Homeopathy is considered a subtle form of placebo by most writers [1], although this claim is contested [2,3]. One of the pillars of homeopathic therapy and practice are homeopathic remedy provings or pathogenetic trials $[4,5]$. In such trials, healthy volunteers ingest a homeopathic substance and report the symptoms they experience. The collection of symptoms from such trials together with a host of toxicological information makes up the homeopathic materia medica, a collection of symptoms produced by substances in healthy individuals. This information is used for treating patients by matching the symptom pictures of patients to the symptoms a particular remedy has produced in volunteers over time. While some of these symptoms are commonplace, each remedy also has very particular, specific symptoms that define the particular pattern of a remedy. Homeopathy can be conceptualised as the art of pattern-recognition on the level of symptomatic changes. There are more than 1,500 remedies in the homeopathic arsenal, about 150 of which are considered so-called polychrests, because they can be used for different and often chronic diseases. Most of them date back to Hahnemann, the founder of homeopathy, himself and have been applied and tested again and again. However, rigorous pathogenetic trials have been mostly inconclusive so far [6-10].

We have reported previously on a new method of combining the quantitative approach of science with the qualitative approach used by homeopathy [11] of collecting many individual, idiosyncratic symptoms $[12,13]$. We were able to show in those pilot studies that homeopathic remedies seem to produce symptoms which are typical for the remedy and distinct from non-specific placebo symptoms, and that in tendency such typical symptoms can be seen more frequently in the group receiving homeopathic remedies. We recently replicated our findings in two separate studies that were analysed conjointly. One of the studies tested two remedies against placebo, the other study used a two-armed design, testing the same remedy as in one of the arms of the three-armed study against placebo. Selection of the remedies, as well as all methods, was strictly blinded. When analysing the remedy that was common to both studies against placebo, we found significantly more symptoms specific for that remedy in the remedy group than in the placebo group. This was the first time such a clear-cut result was seen in a recent, rigorous study [14].

Since the results of our first pilot studies were inconclusive, and some colleagues pointed out that this may have been due to the fact that we had used lesser known and not well studied remedies, and since the remedies used in the second study were new ones, we decided to use major homeopathic polychrests, well known and frequently used remedies. The materia medica of these remedies is considered complete, hence not many new symptoms are to be expected in replication studies.

The study followed the design and the arguments published previously [13]. We wanted to study the hypothesis, whether, using such a methodology, homeopathic remedies administered in an ultramolecular dose, i.e. with no active molecules present, would still produce symptoms different from placebo.

\section{Methods}

Healthy volunteers, medical doctors participating in a homeopathic training course offered by the German Association of Homeopathic Doctors (Zentralverein Deutscher homöopathischer Ärzte), were invited to participate in a Homeopathic Pathogenetic Trial (HPT), as part of their training. As the participants were all medical doctors and the substance used was diluted well beyond Avogadro's number, the study was considered a safe medical self-experiment. Previous ethical advice by a specialised lawyer to the Association responsible for conducting these courses and the ethical committee of the University Hospital of Freiburg (Germany) had resulted in the generic information that such pathogenetic trials, conducted on volunteer medical doctors, are deemed medical self-experiments and hence need not undergo separate ethical scrutiny each time. Conducting such HPTs for training and self-experience purposes has been part of the training to become a homeopathic doctor in Germany and many other countries at least since the training had been formalised in the decades following the Second World War. The procedure has been defined in a consensus protocol recently, which was adopted in the present study [15]. Occasionally, such as here, these experiments have been used for scientific data collection in the framework of a rigorous study. Thus, participants of the training course, all medical doctors with full medical training and with a licence to practice, were invited to participate. They were, of course, free to not participate or to refuse the usage of their data for scientific purposes. They knew that they would then receive either a homeopathic remedy unknown to them and to the proving director, or placebo. They were not told the chance to receive either one or the other.

Potential participants had to be medical doctors of the training programme and had to give informed consent. They were excluded, if any of the following exclusion criteria were present: acute illness, chronic disease necessitating regular medication, intake of conventional medication except contraceptives, pregnancy or nursing, extraordinary strain from family or job demands, intake of any homeopathic remedies at time of trial, intake of homeopathic remedies at C30 up to 4 weeks previously, intake of homeopathic remedies at $\mathrm{C} 200$ up to 2 months previously, intake of homeopathic remedies at $\mathrm{C} 1,000$ or higher up to 3 months previously.

25 out of 59 course participants having given consent were randomised to receive either one of two homeopathic remedies, Natrum muriaticum or Arsenicum album, chosen randomly from a predetermined list of 20 remedies by an independent pharmacist despatching the substances, or an identical placebo. The list contained the names of remedies that are frequently used in homeopathic practice and whose remedy pictures are taught on the course. They are well known and widely applicable: aloe, apis, Arsenicum album, Aurum metallicum, Arsenicum muriaticum, bufo, Carbo vegetabilis, causticum, china, hyoscyamus, ignatia, Kalium carbonicum, lycopodium, mercurius, Natrum muriaticum, Natrum vomica, opium, platina, pulsatilla, thuja. The list of remedies was only known to the study director (HM) and the pharmacist, not to the participants, and not to the study team (HW, RS).

Thus, all participants, the study director (HM) and other personnel involved with the administration of substances were blind as to the precise name of the remedies administered and group allocation. Substances were prepared freshly by Dolisos homeopathic pharmacy, Lausanne, Switzerland, according to the European Homeopathic Pharmacopoeia, and sent in numbered containers to the study site. The randomisation code was created by an independent researcher (RS) from the random algorithm of RITA (Randomization in Treatment Arms) [16]. The code contained three group assignments with random numbers that were used 
Fig. 1. Mean number of symptoms (vertical bars: $95 \%$ confidence intervals) specific for $\mathrm{Ar}$ senicum album or Natrum muriaticum, respectively, and non-specific symptoms in the three experimental groups.

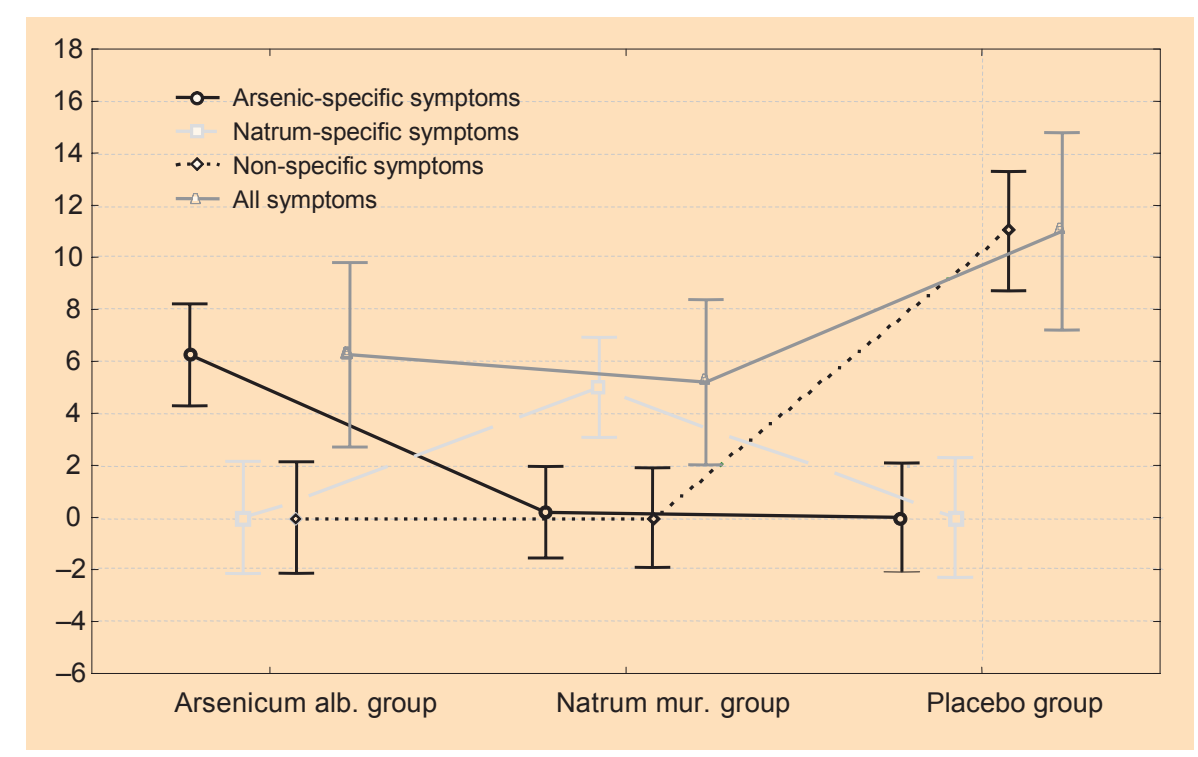

to choose from the containers sent by the pharmacy. The code was kept safely by the study centre. The substances were prepared in $\mathrm{CH} 30$, a potency which had been diluted and succussed (i.e. heavily shaken) 30 times, in a separate glass vial with each dilution step, at a ratio of 1:100. They were then sprinkled over sugar globules, as is the dispensing rule. A potency of $\mathrm{CH} 30$ corresponds to a dilution of $10^{-60}$ (note that this is a dilution well beyond Avogadro's number which is $6,023 \times 10^{23}$, the number of molecules in $1 \mathrm{~mol}$ of substance; hence a dilution beyond $10^{-23}$ is not expected, statistically, to contain any molecules). Placebo was sprinkled with the same amount and batch of alcohol, which is used as the carrier for the homeopathic production process.

Participants were advised to take 5 globules on the first day, $2 \times 5$ globules on the second day, or until symptoms appeared and then stop intake. Symptoms were observed for 2 more days, i.e. 4 days following ingestion. Symptoms were noted down by participants into an unstructured diary, and verified by personal interviews with the proving director each day. After data collection, all symptoms across all subjects were collated according to the familiar head-to-foot scheme. This is a scheme known from homeopathic repertories (i.e. books that are meant to help find the right remedy by ordering symptoms and listing all potential remedies associated with these symptoms). It starts with mental symptoms, followed by symptoms experienced in the head, eyes, ears, mouth and so forth down the anatomical locations of the body and ends with general symptoms such as feelings of heat or cold. That way, all symptoms were de-contextualised from the original volunteer experiencing it and broken down in units familiar to homeopathic practice.

Finally, a materia medica expert otherwise unconnected with the study was given the list of symptoms, ordered according to the head-to-foot scheme, and the names of the remedies tested. The expert was blind to group allocation, and he was not given the original protocols, but a collated list of symptoms which did not allow him to attribute symptoms to individuals, nor to groups. The expert used a commonly used and commercially available computer repertorisation programme (Synthesis by Archibel, Namur, Belgium) to decide for each symptom, whether it is typical for one of the two remedies tested or not. Note that through this method it was impossible for the materia medica expert to second-guess which volunteer might have produced which series of symptoms. He was strictly bound to make a decision for each individual symptom, irrespective of other symptoms.

This procedure yielded our final outcome parameter: the number of symptoms typical for each remedy. This, and the number of untypical symptoms was calculated and submitted to non-parametric statistical testing, using SPSS.

\section{Results}

Altogether, 25 volunteers, 6 men and 19 women, with a mean age of 42.3 years (standard deviation $\mathrm{SD}=6.58$ years), all medical doctors, participated in the experiment. 10 were randomised to receive Natrum muriaticum, 8 to receive Arsenicum album, and 7 to placebo. They experienced altogether 165 symptoms over the course of 4 days. On average they reported 6 symptoms when taking Arsenicum album, 5 symptoms when taking Natrum muriaticum, and 11 symptoms when taking placebo. The results are presented in figure 1, and a selection of typical symptoms is presented in table 1 . As can be seen, symptoms typical for the respective remedy were more frequent both in the Natrum muriaticum group and in the Arsenicum album group, while non-specific symptoms were more frequent in the placebo group. A non-parametric Kruskall Wallis analysis showed significant differences between groups $(\mathrm{p}=0.0002)$, and a pre-planned separate Mann-Whitney tests confirmed that significantly more specific symptoms $(\mathrm{p}<0.001)$ were observed in the respective groups compared with the placebo control group.

\section{Discussion}

To our knowledge this is the first time that in a homeopathic pathogenetic trial (HPT) clear and statistically significant differences could be found in symptoms specific for a remedy between placebo and treatment group, using classical homeopathic remedies and apart from a similar result we found with new remedies [14]. Please observe that the overall number of all symptoms was roughly the same in the homeopathic groups and nearly twice as high in the placebo group, a difference that is obvious but not statistically significant. The statistical difference is only obvious if symptoms specific for the remedy in 
Table 1. Samples of symptoms as described by volunteers in different groups - representative examples ordered according to the traditional head-to-foot scheme

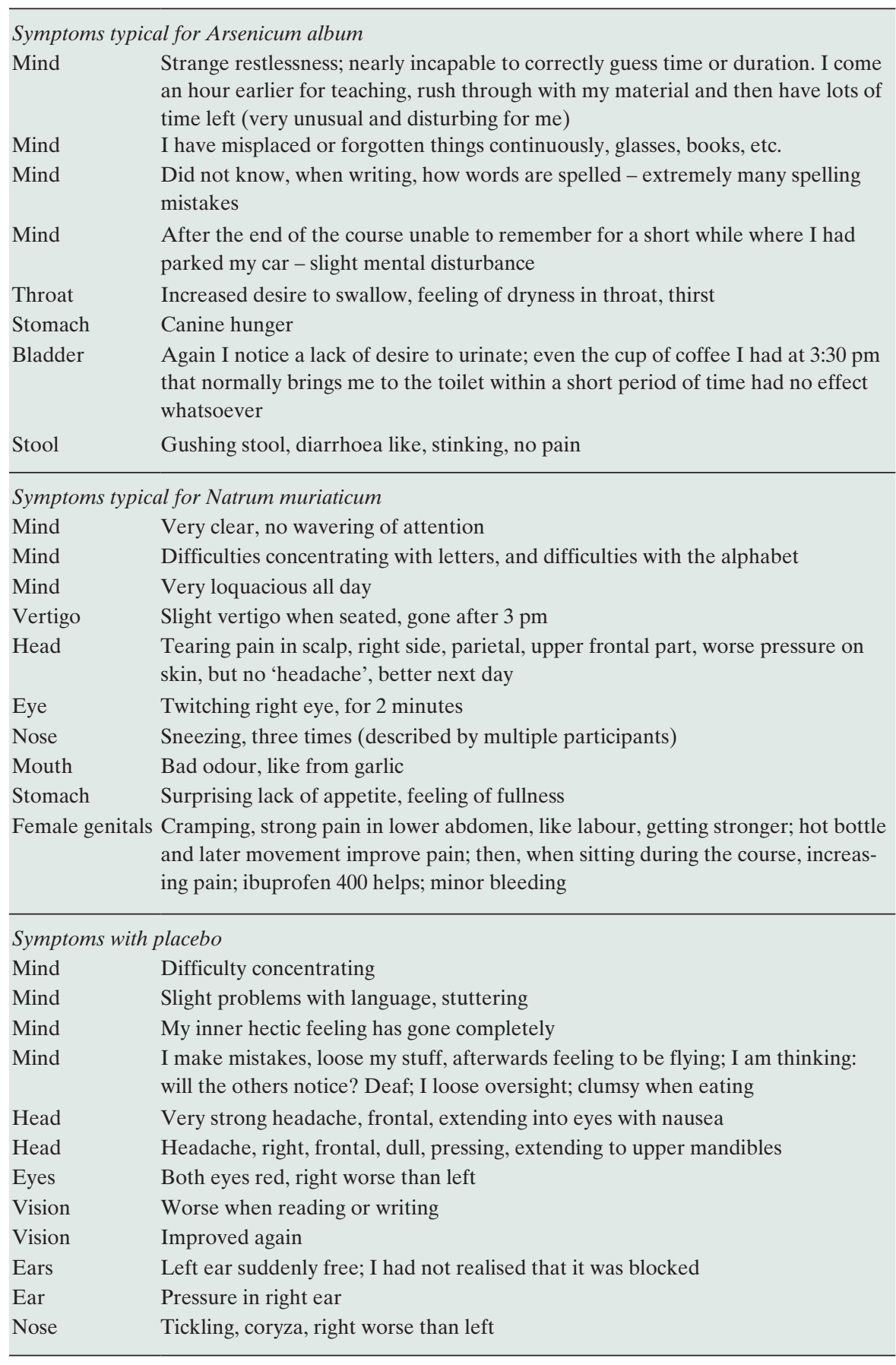

question are counted. What is interesting in this study is the fact that there were virtually no specific symptoms in the placebo group, and no cross-specificity in the two remedy groups, i.e. symptoms that are typical for the other remedy tested, as we found in our previous studies [12-14]. This may have to do with the fact that these well-known remedies have been repeatedly used and tested, such that it is unlikely that new symptoms would arise. Thus, the margin for insecurity on part of the materia medica expert was smaller and made it easier to judge the symptoms. Since both remedies have well-defined and quite distinct remedy pictures, it was easier to not confuse them.
Other rigorous studies have not found a lot of indications that homeopathic remedies produce anything different from placebo symptoms [6, 7, 17-19]. However, these studies used a much cruder approach to data collection, in using predetermined categories of symptoms or global definitions as outcome parameters. In the study reported here, we did not restrict the variability of data. In fact, we encouraged participants to be as precise with their experiential description as possible, collecting a host of qualitative data in the diaries. They were converted into quantitative data only at the final step, where the materia medica expert had to make a decision 
as to whether a particular symptom was a symptom typical for a particular remedy or not.

The latter is clearly the weak link in the methodology, as the result is only as good as the materia medica expert's skill. However, the materia medica expert used a standard computer software repertory that is used in homeopathic practice a lot and that contains all symptoms of all remedies, a reverse version of the homeopathic materia medica. Hence, this final step is very close to standard homeopathic practice and thus ecologically valid, if not completely ideal. We feel that our method offers a benefit over methods hitherto practised. It is faithful to the wide variability and phenomenology observed in homeopathic practice, while at the same time employing the rigour of modern experimental methodology. It might be used to conduct a series of such studies, which would produce essentially similar databases, namely number of symptoms typical for a remedy tested. Such data could be accumulated across studies, independent of remedies tested, and then pooled for final analyses.

It goes without saying, though, that such a method is only applicable, where a remedy picture of a substance has already been worked out through traditional HPT methodology and will not be useful for detecting new remedy pictures or in remedies with limited information. However, where such remedy pictures are known, it is a powerful method for reproving and for using the generic set-up of a HPT for further experimentation.

Our results are unlikely to be due to bias or fraud: Volunteers and investigators did not know which remedies were tested. Hence it was not possible to produce the 'correct' symptoms by suggestion or fake. Everyone involved in the trial itself was blind as to group allocation. Hence, even if the tested remedies had been known, it would not have been possible to cheat, as no one knew which person was receiving which substance. Treatment and control substances were absolutely identical in appearance and taste, the only difference being the potentisation process originating from two separate substances. The products were freshly produced by a wellknown homeopathic pharmacy, according to legal standards applicable in Europe. They were dispatched in coded containers such that no inference could be made from them. The randomisation code was concealed such that nobody involved in the trial had anything to do with the creation of this code or the creation of the experimental groups, or had access to the code. The materia medica expert who determined whether a certain symptom was typical for one of the two remedies or not, was blind as to group allocation, and otherwise not involved with the organisation or conduct of the study. The only way this person could have cheated would have been by having access to the code and coding symptoms, accordingly. This was impossible, as the code existed only in its full version - i.e. allocation of code numbering to remedies - at the research centre and was only fully revealed once the database of symp- toms was classified by the materia medica expert and the statistical analysis had been done blindly. Thus, to the best of our knowledge these data are valid, if surprising.

One might argue that a lot of HPTs are being conducted in the context of such trainings, and hence, just by chance, one might pick the right symptoms in the right group. This is true. But one would have to consider the counterargument that, if fully blinded, the chances to experience just those symptoms that count as symptoms typical for one remedy, are very small, considering the host of symptoms one might experience. The gist of specific homeopathic symptoms is that they are quite unusual and distinct (see table). For instance, a typical symptom of Natrum muriaticum might be bleeding cracks in the lips, or the unwillingness to talk to someone about one's problems and find consolation, or feeling better when fasting the whole day. While these symptoms are not infrequent, they would have to be rather new and unusual in a trial participant who is otherwise healthy in order to count as remedy symptoms. Each remedy has such typical symptoms associated with it. To experience just these symptoms by chance in the right group, while otherwise healthy, is a very unlikely occurrence. It is difficult to quantify this as no one knows the baseline probability for such occurrences.

Just how unlikely our result is by chance is quantified by the omnibus statistical test we used, namely 2 in 10,000. If one wants to use the more conservative testing of single groups against placebo and correct for multiple testing it would still be a small chance of 2 in 1,000. While chance can never be completely ruled out by research, we feel that we have produced valid data that show that homeopathic remedies administered to healthy volunteers can, at least sometimes, produce symptoms qualitatively different from symptoms produced by placebo in the same study and typical for the remedy tested.

We conclude, then, the jury is still open, whether homeopathy is only placebo or more. Our data suggest it is not placebo. They encourage an in-depth scrutiny.

\section{Acknowledgement}

We are grateful to Dr. Häcker-Strohbusch who helped organise this study during the training course of the German Homoepathic Physicians in Stuttgart-Hohenheim, and to Dr. Reimund Wagner who matched symptoms to remedies. We thank Dolisos, $\mathrm{CH}$-Lausanne, who produced and donated the remedies.

Sources of Funding: HW and RS were supported by the Samueli Institute.

\section{Competing Interest: None.}

Author Contributions: HW developed the design of this study, oversaw the study process and wrote the final manuscript. RS did the statistical analysis, wrote parts of the manuscript, participated in discussion of the data and editing of the final manuscript. HM organised the study and the data collection process, as well as the qualitative analysis of the study. 


\section{References}

1 Shang A, Huwiler-Münteler K, Nartey L, Jüni P, Dörig S, Sterne JAC, Pewsner D, Egger M: Are the clinical effects of homeopathy placebo effects? Comparative study of placebo-controlled trials of homoeopathy and allopathy. Lancet 2005;366:726-732.

2 Walach H, Jonas W, Lewith G: Are the clinical effects of homoeopathy placebo effects? Comparative study of placebo-controlled trials of homoeopathy and allopathy (letter). Lancet 2005;366:2081.

-3 Fisher P, Bell IR, Belon P, Bolognani F, Brands M, Connolly T, Dantas F, Endler PC, de Freitas C, Dean ME, Eizayaga F, Eizayaga J, Jansen JP, Jobst K, D. K, Lewith G, Mathie R, Mercer SW, Nicolai T, Oberbaum M, Peters D, Poitevin B, Riley D, Rutten L, Schwartz G, Spence D, Steinsbekk A, Thompson E, Walach H, Whitehouse PJ: Are the clinical effects of homoeopathy placebo effects (letter)? Lancet 2005;366:2082.

4 Dantas F: How can we get more reliable information from homoepathic pathogenetic trials? A critique of provings. Br Hom J 1996;85:230-236.

5 Walach H: The pillar of homoeopathy: Remedy provings in a scientific framework. Br Hom J 1997;86:219-224.

6 Walach H: Does a highly diluted homoeopathic drug act as a placebo in healthy volunteers? Experimental study of Belladonna C30. J Psychosom Res 1993;37:851-860.
7 Walach H, Köster H, Hennig T, Haag G: The effects of homeopathic belladonna $30 \mathrm{CH}$ in healthy volunteers - a randomized, double-blind experiment. J Psychosom Res 2001;50:155-160.

8 Vickers AJ, Van Haselen R, Heger M: Can homeopathically prepared mercury cause symptoms in healthy volunteers? A randomized, double-blind placebo-controlled trial. J Altern Complement Med 2001;7:141-148.

9 Vickers A: Independent replication of pre-clinical research in homoeopathy: A systemativ review. Forsch Komplementarmed 1999;6:311-320.

10 Dantas F, Fisher P, Walach H, Wieland F, Rastogi DP, Texeira H, Koster D, Jansen JP, Eizayaga J, Alvarez MEP, Marim M, Belon P, Weckx LLM: A systematic review of homeopathic pathogenetic trials published from 1945 to 1995 . Homeopathy 2007; 96:4-16.

11 Walach H, Schüppel R: Homöopathieforschung eine Taxonomie. Forsch Komplementarmed 1997;4: 344-347.

12 Walach H, Sherr J, Schneider R, Shabi R, Bond A, Rieberer G: Homeopathic proving symptoms: result of a local, non-local, or placebo process? A blinded, placebo-controlled pilot study. Homeopathy 2004;93:179-185.

13 Möllinger H, Schneider R, Löffel M, Walach H: A double-blind, randomized, homeopathic pathogenetic trial with healthy persons: Comparing two high potencies. Forsch Komplementarmed Klass Naturheilkd 2004;11:274-280.
4 Walach H, Möllinger H, Sherr J, Schneider R: Homeopathic pathogenetic trials produce more specific than non-specific symptoms: Results from two double-blind placebo controlled trials. J Psychopharmacol 2008;22:543-552.

15 Deutscher Zentralverein homöopathischer Ärzte (DZvhÄ): Homöopathische Arzneimittelprüfungen. Prinzipien, Durchführung, Dokumentation. Ergebnisse einer Konsensuskonferenz des Zentralvereins homöopathischer Ärzte 1998-2000. Köthen, DZVhÄ, 2002.

16 Pahlke F, König IR, Ziegler A: Randomization in Treatment Arms (RITA): Ein Randomisierungsprogramm für klinische Studien. Informatik Biometrie Epidemiol Med Biol 2004;35:1-22.

17 Brien S, Prescott P, Owen D, Lewith G: How do homeopaths make decisions? An exploratory study of inter-rater reliability and intuition in the decision making process. Homeopathy 2004;93:125-131.

18 Goodyear K, Lewith G, Low JL: Randomised double-blind placebo controlled trial of homoeopathic proving for Belladonna C30. J R Soc Med 1998;19: 579-582.

19 Lewith GT, Brien S, Hyland ME: Presentiment or entanglement? An alternative explanation for apparent entanglement in provings. Homeopathy 2005 94:92-95. 